\title{
Post-surgical evaluation of dry socket formation after surgical removal of impacted mandibular third molar- A prospective study
}

\author{
Vijay Kumar $^{1 *}$, Manoj Chaudhary ${ }^{2}$, Sanjay Singh ${ }^{3}$, Gokkulakrishnan ${ }^{2}$ \\ ${ }^{1}$ R. D. Dental Hospital \& Research Centre, Patna, India \\ ${ }^{2}$ Department of Oral \& Maxillofacial Surgery, Kothiwal Dental College \& Research Centre, Moradabad, India \\ ${ }^{3}$ Department of Oral \& Maxillofacial Surgery, Faculty of Dentistry, Jamia Milia Islamia University, New Delhi, India \\ Email: ${ }^{*}$ vijaypraveenmds@gmail.com
}

Received 2 September 2012; revised 4 October 2012; accepted 4 October 2012

\begin{abstract}
Aims \& Objectives: This study was performed to evaluate the incidence, risk factors (age, sex, infection, radiographic difficulty of the extraction, tobacco use) contributing to the development of dry socket and clinical features following surgical removal of impacted mandibular third molar. Materials and Methods: The study included 63 patients during period of September 2009 to September 2011 in the age group of 18 to 53 years with impacted mandibular third molars all of which were surgically removed under local anesthesia by the same operator. Following surgery all patients received a single dose of $\mathbf{4} \mathbf{~ m g}$ corticosteroid intravenously and similar prescriptions for analgesics, antibiotics and postoperative instructions. All patients were reviewed at 3rd and 7th day postoperatively. Results: In this study incidence of dry socket was $6.3 \%$. We also noticed onset of symptom mostly appeared within $\mathbf{4 8}$ hours. Postoperatively pain, bare bone and halitosis were the most significant clinical feature at 3rd postoperative day and pain, empty socket and bare bone were most significant clinical feature at 7th postoperative day. Variables like right 3rd molar impaction, patients mean age between 19 - 32 years, female, preoperative infection, radiographically difficult impaction and habitual tobacco users showed a higher incidence of dry socket formation. Conclusion: Incidence of dry socket formation is multifactorial and therefore, there is need to evaluate all factors, with special attentions in handling these patients to reduce the incidence of dry socket formation.
\end{abstract}

Keywords: Dry Socket; Third Molar Impactions; Third Molar Surgery

${ }^{*}$ Corresponding author.

\section{INTRODUCTION}

"Dry socket" has probably been around since the practice of exodontia began [1-3]. It is a very common and unpleasant local complication after surgical removal of impacted mandibular third molar [4-7]. Etiology of dry socket is multifactorial [8] and various risk factors are age, sex, tobacco use, radiographic difficulty of extraction, infection of alveolus etc. The two most common explanations as to why the mandibular third molar site is the most affected by dry socket are increased trauma and increased risk of bacterial contamination $[4,8]$. The clinical appearance of this disease is well known and was first described by Crawford in 1896 [4]. The clinical feature of dry socket presents as necrosis and disintegration of the originally occurred blood clot [4,9-12], alveolus is empty, with completely or partially denuded [4,10,13], very sensitive bone surfaces, covered by a greyish yellow layer of detritus and necrotic tissues [4] and severe throbbing pain from the extraction socket that radiates towards different adjacent parts or organs [4,9,10,12-15]. This usually occurs 2 - 3 days after tooth extraction and last several days to weeks [4]. The previous studies showed that incidence of dry socket after the surgical removal of impacted mandibular 3rd molar ranged from $0 \%$ [16] to $44.64 \%$ [3] and incidence of Dry socket was " $1 \%$ to $3 \%$ " $[3,6]$ for all extractions.

This study was performed to evaluate the incidence, risk factors (age, sex, infection, radiographic difficulty of the extraction, tobacco use) contributing to the development of dry socket and clinical feature following surgical removal of impacted mandibular third molar in a control condition.

\section{MATERIAL AND METHODS}

This prospective study was conducted in the Department of Oral and Maxillofacial Surgery, Kothiwal Dental Col- 
lege \& Research Centre, Moradabad. 63 consecutive patients seen for surgical removal of impacted mandibular third molar were included in this study. The subjects were screened for any local or systemic contraindications for the surgery under local anesthesia, by detailed history, systemic and local examination and investigations.

\subsection{Inclusion Criteria}

Patients age of 18 years and above, patients with at least one impacted mandibular 3rd molar and patients free of any serious systemic illness.

\subsection{Exclusion Criteria}

Patients with serious systemic illness that complicates surgery, pregnant or lactating females and patients not interested to participate in the study.

\subsection{Surgical Procedure}

Surgery was performed in a standardized manner, by a single operator using a similar technique. In all patients, intraoral preparation was done with mixture of betadine solution and normal saline (1:1 ratio) while extraoral preparation was done with $5 \%$ standard betadine solution and the patient was draped with sterile drapes. Xylocain $2 \%$ with 1:200,000 adrenaline was used to give classic inferior alveolar, lingual and long buccal nerve blocks for all patients. Incision started from a point about 6.4 mm down in the buccal sulcus at the junction of posterior and middle third of the second molar. The anterior line of the incision passes upward to the distobuccal angle of the second molar at the gingival margin. Here the course of the incision passes cervically behind the tooth to the middle of its posterior surface if the third molar is unerupted. From this point or an alternative position of election on the distal aspect of the second molar, the cut is taken backwards and buccally but not directed straight up the ramus. In its final continuation, the incision should penetrate the cheek tissue only at the mucosal depth and extend laterally for about $25.4 \mathrm{~mm}$ [17]. Then full mucoperiosteal flap was reflected from anterior to posterior direction with the help of Dial's periosteal elevator and buccal retractor was placed under the flap to expose the operative field. In presence of copious irrigation, required amount of bone was removed from its buccal and distal aspect upto cemento-enamel junction with straight fissure bur no. 702 at low speed of two to four thousand rpm. In cases, where sectioning of the crown of the tooth was required, it was achieved by making groove in the crown with the help of bur and final sectioning was achieved using chisel and mallet. After removing adequate amount of bone, tooth was delivered by using elevators using minimal force (Warwick James, cryer elevators or coupland elevators) at the purchase point made at the mesial aspect of the third molar or the furcation area or the buccal aspect of tooth. After tooth was elevated from its socket the tooth and its roots were examined properly to ensure that the whole tooth was removed. The wound was gently irrigated with sterile saline solution. Residual tooth sac from distal surface of mucosa, granulation tissue and small-detached fragments of bone and bone dust were removed from socket and from beneath the soft tissue flap. Sharp irregular edges and interradicular bone were trimmed. Cross cut vulcanite bur was used for final smoothening of the socket margins. Bleeding was controlled by pressure packs and the wound was again irrigated with 5\% standard betadine solution and saline, in equal proportions. Finally wound was closed with 3-0 silk suture. After operation $4 \mathrm{mg}$ of corticosteroid was administrated intravenously and all patients were given similar prescriptions for analgesics (combination of $50 \mathrm{mg}$ Diclofenac sodium and $500 \mathrm{mg}$ Pracetamol) 1tab BID and antibiotics (500 mg Amoxicillin) 1cap TID for at least 5 days. They were instructed strictly to bite firmly for 30 minutes, on sterile gauge placed over the wound, to avoid rinsing for the next 24 hrs, to take cold liquids for the first 24 hrs followed by warm saline rinses and $0.2 \%$ chlorhexidine rinses intermittently after 24 hrs to keep the area clean of any debris and to avoid tobacco intake for at least 7 days after the surgery.

During the first postoperative review appointment (after 3rd day of surgery), I am recording clinical features (time of onset of symptoms, sever throbbing pain that was not relived by above mentioned analgesics, empty socket, bare bone, halitosis etc) and risk factors (age, sex, infection, radiographic difficulty of the extraction, tobacco use) contributing to the development of dry socket. In case of alveolar osteitis formation, the treatment was warm saline irrigation followed by Zinc oxide Eugenol (ZnO-E) packing was used to decrease the symptoms and allowing an adequate environment for healing. Finally, the patients were reviewed at the 7th day of surgery and suture removal was done and further wound evaluation was conducted in similar manner.

\section{RESULTS}

A total of 63 patients undergoing surgical removal of impact mandibular third molar were enrolled in the study. The patients were placed in two groups according to status of development of dry socket. Majority of subjects 59 of $63(93.7 \%)$ did not develop dry socket and were placed in control group while only 4 of 63 (6.3\%) subjects developed dry socket and comprised the study group (Table 1).

There was no statistically significant deference between the control group and study group with respect to 
Table 1. Group wise Distribution $(n=63)$.

\begin{tabular}{cclcc}
\hline S.No & Group & Description & No. of patients & Percentage \\
\hline 1. & Control & Subjects undergoing 3rd mandibular extraction and not developing dry socket & 59 & 93.7 \\
2. & Study & Subjects undergoing 3rd mandibular extraction and developing dry socket & 4 & 6.3 \\
\hline
\end{tabular}

patient distribution according to the monitored risk factors of age, sex, infection, radiographic difficulty of the extraction, tobacco use of the impacted mandibular 3rd molar extraction.

The mean age (Mean \pm SD) of control group were $29.14 \pm 7.98$ and study group were $24.25 \pm 5.50$ years. Hence the mean age range in study group was 19 to 30 years, have higher incidence of dry socket ( $p=0.169)$ whereas mean PDI (Pederson difficulty index) was 6.25 \pm 1.50 hence mean PDI range was 5 to 8 , had higher incidence of dry socket ( $p=0.107)$.

Dry socket developed in female patients in 3 of 30 surgical sites (10\%), whereas alveolar osteitis developed in 1 of 33 surgical sites (3.03\%) in male patients. This trend towards a higher incidence of dry socket in the female patients was not statically significant ( $p=0.271)$.

No statically significant deference was found between the rates of dry socket formation as a result of preexisting infection. In 1 of 45 surgical sites was free from preexisting infection (2.22\%) alveolar osteitis developed, compared with 3 of 18 surgical sites have preexisting infection (16.67\%) ( $p=0.067)$.

Three radiographically difficult extraction groups were comparing to see what effect radiographically difficult extraction have on the incidence of dry socket. Minimum radiographically difficult extractions had no incidence of dry socket whereas Moderate radiographically difficult extraction had an incidence of 9.52\% (2/21) and Very radiographically difficult extraction had an incidence of $15.38 \%$ (2/13). This trend for increase incidence in more radiographically difficult extraction was not statically significant ( $p=0.128)$.

In non tobacco user patients dry socket developed in 3 of 54 surgical sites (5.56\%) whereas in tobacco user patients its incidence had (11.11\%) 1/9 surgical sites. This trend of increased incidence in non tobacco user was not statically significant ( $p=0.469)$.

Regarding onset of symptoms, (75\%) 3 of 4 patients developed dry socket within 48 hrs whereas (25\%) 1 of 4 patients developed dry socket within 72 hrs (Table 2).

On third post-operative day, none of the cases in control group had any incidence of complications. However, in study group, 3 patients had pain, bare bone and halitosis and one patient had empty socket. For pain, bare bone and halitosis, the difference between two groups was significant statistically ( $p<0.001$ ) (Table 3).

On day 7, all the subjects in study group had pain,
Table 2. Chronology of onset of symptoms $(n=63)$.

\begin{tabular}{cccc}
\hline S.No & Time interval & $\begin{array}{c}\text { No. of patients showing } \\
\text { onset of symptoms }\end{array}$ & Percentage \\
\hline 1. & Immediately & 0 & 0 \\
2. & $24 \mathrm{hrs}$ & 0 & 0 \\
3. & $48 \mathrm{hrs}$ & 3 & 4.8 \\
4. & $72 \mathrm{hrs}$ & 1 & 1.6 \\
5. & Others & 0 & 0 \\
\hline
\end{tabular}

empty socket and bare bone; half (50\%) subjects had halitosis. In control group none of the patients had any complication. On comparing the two groups statistically, a significant difference was observed for all the parameters studied ( $<$ 0.05) (Table 4).

\section{DISCUSSION}

Dry socket is the most common complication after surgical removal of impacted mandibular third molars [4-7] Birn H. in 1973 reported that fibrinolysis is the provoking factor in Fibrinolytic alveolitis (FA), trauma or infection or both may be the etiology of dry socket [4]. After two decades Wong J. D. in 1993 reviewed alveolar osteitis and summarized two most common explanations as to why the mandibular third molar site is most affected by alveolar osteitis, one was increased trauma and the other reason is increased risk of bacterial contamination [8].

Exact pathogenesis of dry socket is not known but possible pathogenesis of dry socket is high fibrinolytic activity in and around the alveolous. Due to excessive trauma or infection or both, there may be bone marrow inflammation in the alveolus. Later on they release stable tissue activator. This stable tissue activator is responsible to convert plasminogen into plasmin. Finally, plasmin release kinins by two mechanisms, First mechanism explains that plasmin directly gets converted into kinins and in second mechanism they cause clot dissolution that is responsible for release of kinins, which induces violent pain in this disease. Onset of FA may vary, but most often takes place on the second day postoperatively because clot contains antiplasmin which must be used up before dissolution of the clot takes place [4].

Another possible Pathophysiology was given by Nitzan in 1983. They reported that T. denticola is the only one saprophyte found in the sockets of established cases of alveolar osteitis. However, in clinical trials after application of an antianerobic antibiotic (Metronidazole) 
Table 3. Distribution of subjects according to post-operative symptoms on third postoperative day $(\mathrm{n}=63)$.

\begin{tabular}{cccccccc}
\hline \multirow{2}{*}{ S.No. } & Post-op. complications & \multicolumn{2}{c}{ Control $(\mathrm{n}=59)$} & \multicolumn{2}{c}{ Study Group $(\mathrm{n}=4)$} & \multicolumn{2}{c}{ Significance of difference (Fisher exact test) } \\
\cline { 3 - 7 } & No. & $\%$ & No. & $\%$ & $\chi^{2}$ & \multicolumn{2}{c}{$p$} \\
\hline 1. & Pain & 0 & 0 & 3 & 75.0 & 43.463 & 0.001 \\
2. & Empty socket & 0 & 0 & 1 & 25.0 & 14.988 & $<.063$ \\
3. & Bare bone & 0 & 0 & 3 & 75.0 & 43.463 & $<0.001$ \\
4. & Halitosis & 0 & 0 & 3 & 75.0 & 43.463 & $<0.001$ \\
5. & Others & 0 & 0 & 0 & 0 & - & - \\
\hline
\end{tabular}

Table 4. Distribution of subjects according to post-operative symptoms on seventh postoperative day ( $\mathrm{n}=63$ ).

\begin{tabular}{cccccccc}
\hline \multirow{2}{*}{ S.No. } & Post-op. complications & \multicolumn{2}{c}{ Control $(\mathrm{n}=59)$} & \multicolumn{2}{c}{ Study Group $(\mathrm{n}=4)$} & \multicolumn{2}{c}{ Significance of difference (Fisher exact test) } \\
\cline { 3 - 7 } & & No. & $\%$ & No. & $\%$ & $\chi^{2}$ & \multicolumn{1}{c}{$p$} \\
\hline 1. & Pain & 0 & 0 & 4 & 100 & 63.000 & $<0.001$ \\
2. & Empty socket & 0 & 0 & 4 & 100 & 63.000 & $<0.001$ \\
3. & Bare bone & 0 & 0 & 4 & 100 & 63.000 & $<0.001$ \\
4. & Halitosis & 0 & 0 & 2 & 50.0 & 30.467 & 0.003 \\
5. & Others & 0 & 0 & 0 & 0 & - & - \\
\hline
\end{tabular}

there has been less incidence of alveolar osteitis. On basis of this finding Nitzan concluded that formation of dry socket was multifactorial and main predisposing factors were sex, age, extraction sites, trauma/difficulty of extraction and smoking [8].

Many authors have stated that patients diagnosed with dry socket have at least two of the following signs and symptoms: Empty socket and Pain in or around the socket within one week of the extraction $[4,13]$.

Postoperative complications after surgical removal of impacted mandibular third molar are best managed by per-operative instructions e.g. proper patient education, atraumatic surgical technique, antibiotics, analgesics and steroids admistration [18]. Proper patient education (post operative instruction) and atraumatic surgical technique were followed as discussed in material and methods that may reduces postoperative complications $[9,18]$, administration of antibiotics reduces the incidence of wound infection and alveolar osteitis [19,20], analgesics may be helpful in reducing post-operative swelling and pain [18] and single dose of pre- or peri-operative administration of Dexamethasone has been shown to reduce swelling and discomfort [18,21,22].

In dry socket, the primary aim of treatment is pain relief and empirical treatment with a variety of socket dressing (Zinc oxide eugenol pack, collagen paste, fibrin sealants, iodoform gauze and whiten varnish) is the main stay of management. Zinc oxide eugenol packing is popular because of their clinical effectiveness in relieving the pain in the dry socket. In other hand bland, non irritants, obtundant dressings such as collagen paste, fi- brin sealants, iodoform gauze and whiten varnish shows promise; as these do not retard socket healing in the same way as Zinc oxide eugenol packing. But disadvantage of course, is the lack of any analgesics properties. Perhaps combinations with a proven topical anesthetic agents and analgesics are the future for such medications. Finally the host healing potential determines the severity and duration of the condition [8,23].

According to previous studies the incidence rate of dry socket formation after surgical removal of impacted mandibular third molar has been documented from low $(0 \%)$ [16] to high (44.46\%) [3]. A possible explanation for this wide range may be found in the lack of uniform diagnostic criteria employed by various authors. In the present study, out of 63 patients, only 4 (6.3\%) subjects developed dry socket, which is also representative of previous literature. Also study conducted by Benediktsdottir I.S. et al. in 2004, reported that incidence of dry socket was $5.90 \%$ after surgical removal of 388 cases of impacted mandibular third molar [24]. Incidence of dry socket in the present study was higher due to small sample size.

In the present study, mean age group was $24.25 \pm 5.50$. Hence the mean age range was 19 to 30 years for study group. This was similar to study conducted by Birn H [4]. He reported that incidence of dry socket formation was directly proportional to the stable tissue activator which is predominantly found in connective tissue type of bone marrow between the age of 20 - 40 years. But before 18 years of age, bone marrow is hemapoietic type and after 40 years bone marrow changes to fat marrow therefore incidence of Fibrinolytic Alveolitis was minimum or 
none because of absence of stable tissue activator. Hence incidence of dry socket was more common in this age group.

In the present study incidence of dry socket in female patients was 3 (75\%) whereas 1 (25\%) in male patients. This indicates female predominance of dry socket which was a common finding in the study conducted by Larsen P. E. et al. [6], Sheikh M. A. et al. [15], Benediktsdottir I. S. et al. [24], Rood J. P. et al. [25], Al Jadid O. G. [26], Bortoluzzi M. C. et al. [27] and Ahmed A. et al. [28]. This high incidence of dry socket in female patient was due to use of oral contraceptives which causes increased fibrinolytic activity associated with higher estrogen level [29].

In present study, higher incidence of dry socket was found in cases of pre-existing infection 3 (75\%) whereas $1(25 \%)$ in normal case which was similar to study by Birn H [4] Susarla S. M. et al. [12], Cardoso C. L. et al. [14], Krekmanov L. et al. [20,30], Rood J. P. et al. [25], Knoedler D. et al. [31], Khorasani M. [32] and Chuang S. K. et al. [33] they also reported the higher incidence of dry socket in cases of pre-existing infection. Birn H. [4] reported that pre-existing infection causes inflammation of bone marrow that was responsible for the release of stable tissue activator factor which finally causes alveolar osteitis.

In present study the mean PDI (Pederson difficulty index) was $6.25 \pm 1.50$. It ranged between 5 to 8 , which indicates moderately difficult to very difficult impactions and was equally distributed, this was similar to the study conducted by Yuasa H. et al. [34] and Benediktsdottir I. S. et al. [24] they also observed that the incidence of dry socket was more in cases of radiographically difficult impactions scored by PDI which was similar to our findings.

In the present study tobacco use was not significantly related to incidence of dry socket formation after 3rd molar surgery, which was similar to study conducted by Biesbrock A. R. et al. [35]. However most authors observed that incidence rate of dry socket formation was significantly high in habitual tobacco users. In the present study the incidence rate of dry socket formation was not significant with tobacco use as this might be due to strict postoperative instruction of stopping tobacco use for 7 days. Al-Belasy F. A. [36] and Balaji S. M. [37] have also observed that incidence of dry socket formation decreases after cessation of tobacco use.

Many previous studies have reported that onset of dry socket was 1 - 3 days after tooth extraction $[4,9,12,15,25$, 38] and within a week almost all cases registered [9]. In the present study, in 3 (4.8\%) patients onset of symptoms was observed at $48 \mathrm{hrs}$. In 1 (1.6\%) patients it was after 72 hrs which is similar to previous studies. Onset of fibrinolytic alveolitis may vary, but most often takes place on the second day postoperatively. Clot contains antiplasmin which must be used up before dissolution of the clot can takes place [4].

In a study conducted by Blum I. R. in 2002, dry socket patients had at least two of the following signs and symptoms: that is empty socket, pain in or around the socket, with or without halitosis [13]. In the present study we found that pain, bare bone, and halitosis were present in three patients on 1st postoperative visit (3rd day) and 1 patient had empty socket which was similar to above observations. These findings were consequence of inflammatory reactions.

In the present study on 2nd postoperative visit all subjects in study group had pain, empty socket and bare bone but only $50 \%$ subjects had halitosis. Out of these findings, pain was common in study by Birn H. [4], Pitekova L. [7], Blum I. R. [9], Bouloux G. F. et al. [10], Susarla S. M. et al. [12], Cardoso C. L. et al. [14], Sheikh M. A. et al. [15] and Ruvo T. A. et al. [39] empty socket was common with the study of Blum I. R [9] and Bouloux G. F. et al. [10] and bare bone was common finding of Birn H [4], Bouloux G. F. et al. [10], Mercier P. et al. [11], Susarla S. M. et al. [12] and Sheikh M. A. et al. [15]. Except halitosis, which was a common finding with the study of Blum I. R. [9] none of the patients in our study group had any other complications.

In the present study all cases of dry socket were treated with warm saline irrigation and Zinc oxide eugenol packing and it was observed that this relieves acute pain episode.

The higher incidence of dry socket formation observed in our study was among young adults, especially females on right side of mandible. Those were radiographically difficult impactions, with pre-existing infection and were habitual tobacco users. Therefore incidence of dry socket formation is multifactorial and care has more to be given to patients with predisposing factors to reduce the incidence rate of dry socket formation.

\section{SUMMERY \& CONCLUSION}

In our study we found that incidence of dry socket was (6.3\%) after surgical removal of impacted mandibular third molars. We also noticed onset of symptoms mostly appears within 48 hours postoperatively, along with pain, bare bone and halitosis, on 3rd postoperative day. Pain, empty socket and bare bone were most significant clinical features on 7th postoperative day. Variables like patients mean age between 19 - 30 years; females, preoperative infection, radiographically difficult impaction and habitual tobacco use are considered as pre disposing factors and are related to higher incidence of dry socket formation. In present study all cases of dry socket were treated with warm saline irrigation with Zinc oxide 
eugenol packing and it was observed that this procedure relieved acute pain episodes.

The higher incidence of dry socket formation observed in our study was among young adults, especially females. Those were radiographically difficult impactions, with pre-existing infection and were habitual tobacco user. Therefore incidence of dry socket formation is multifactorial and more care has to be taken in these patients to reduce the incidence of dry socket formation.

\section{REFERENCES}

[1] Al-Saffar, M.T., Al-Sandook, T.A. and Suleiman M.S. (2008) Protective effect of topical ibuprofen against dry socket. Al-Rafidain Dentak Journal, 8, 136-143.

[2] Fridrich, K.L. and Olson, R.A.J. (1990) Alveolar osteitis following surgical removal of mandibular third molars. Anesthesia Progress, 37, 32-41.

[3] Schow, S.R. (1974) Evaluation of post-operative localized osteitis in mandibular third molar surgery. Oral Surgery, Oral Medicine, Oral Pathology, 38, 352-358. doi:10.1016/0030-4220(74)90360-0

[4] Birn, H. (1973) Etiology and pathogenesis of fibrinolytic alveolitis (“dry socket”). International Journal of Oral Surgery, 2, 211-263.

doi:10.1016/S0300-9785(73)80045-6

[5] Goldman, D.R., Kilgore, D.S., Panzer, J.D. and Atkinson, W.H. (1973) Prevention of dry socket by local application of lincomycin in Gelfoam. Oral Surgery, Oral Medicine, Oral Pathology, 35, 472-474. doi:10.1016/0030-4220(73)90004-2

[6] Larsen, P.E. (1992) Alveolar osteitis after surgical removal of impacted mandibular third molars: Identification of the patient at risk. Oral Surgery, Oral Medicine, Oral Pathology, 73, 393-397. doi:10.1016/0030-4220(92)90312-E

[7] Pitekova, L., Satko, I. and Novotnakova, D. (2010) Complications after third molar surgery. Bratislavské Lekárske Listy, 111, 296-298.

[8] Wong, J.D. (1993) Alveolar osteitis: A review. Dentistry Library University of Sydney, Sydney.

[9] Blum, I.R. (2002) Contemporary views on dry socket (alveolar osteitis): A clinical appraisal of standardization, aetiopathogenesis and management: A critical review. International Journal of Oral and Maxillofacial Surgery, 31, 309-317. doi:10.1054/ijom.2002.0263

[10] Bouloux, G.F., Steed, M.B. and Perciaccante, V.J. (2007) Complication of third molar surgery. Oral \& Maxillofacial Surgery Clinics of North America, 19, 117-128. doi:10.1016/j.coms.2006.11.013

[11] Mercier, P. and Precious, D. (1992) Risks and benefits of removal of impacted third molars: A critical review of the literature. International Journal of Oral and Maxillofacial Surgery, 21, 17-27. doi:10.1016/S0901-5027(05)80447-3

[12] Susarla, S.M. Blaeser, B.F. and Magalnick, D. (2003) Third molar surgery and associated complications. Oral
\& Maxillofacial Surgery Clinics of North America, 15, 177-186.

[13] Younis, M.H.A. and Abu-Hantash, R.O. (2011) Dry socket: Frequency, clinical picture, and risk factors in a Palestinian Dental Teaching Center. The Open Dentistry Journal, 5, 7-12. doi:10.2174/1874210601105010007

[14] Cardoso, C.L., Rodrigues, M.T.V., Ferreira Junior, O., Garlet, G.P. and De-Carvalho, P.S.P. (2010) Clinical concepts of dry socket. Journal of Oral and Maxillofacial Surgery, 68, 1922-1932. doi:10.1016/j.joms.2009.09.085

[15] Sheikh, M.A., Kiyani, A., Mehdi, A. and Musharaf, Q. (2010) Pathogenesis and management of dry socket (alveolar osteitis). Pakistan Oral \& Dental Journal, 30, 323326.

[16] Krogh, H.W. (1948) Prevention of dry sockets. Journal of Dental Research, 27, 3-8. doi:10.1177/00220345480270010601

[17] Killey, H.C. and Key, L.W. (1975) The impacted wisdom tooth.

[18] Ministry of Health Malaysia (2005) Clinical practice guide line. Management of unerupted and impacted third molar teeth.

[19] Conaty, S., Hoang, H., Kirshen, D., Kwong, C., Schroeder, E. and Stromme, A. (2010) Pre and post-operative antibiotic prophylaxis in the prevention of complications following third molar surgery. University of Toronto, Faculty of Dentistry, March.

[20] Krekmanov, L. and Hallander, H.O. (1979) Relationship between bacterial contamination and alveolitis after third molar surgery. International Journal of Oral Surgery, 9, 274-280. doi:10.1016/S0300-9785(80)80034-2

[21] Tiigimae-Saar, J., Leibur, E. and Tamme, T. (2010) The effect of prednisolone on reduction of complaints after impacted third molar removal. Stomatologija, Baltic Dental and Maxillofacial Journal, 12, 17-22.

[22] Tiwana, P.S., Foy, S.P., Shugars, D.A., Marciani, R.D., Phillips, C. and White, R.P. (2005) The impact of intravenous corticosteroids with third molar surgery in patients at high risk for delayed health-related quality of life and clinical recovery. Journal of Oral and Maxillofacial Surgery, 63, 55-62. doi:10.1016/j.joms.2004.01.029

[23] Noroozi, A.R. and Philbert, R.F. (2009) Modern concepts in understanding and management of the "dry socket" syndrome: Comprehensive review of the literature. Oral Surgery, Oral Medicine, Oral Pathology, Oral Radiology and Endodontology, 107, 30-35. doi:10.1016/j.tripleo.2008.05.043

[24] Benediktsdottir, I.S., Wenzel, A., Petersen, J.K. and Hintze, H. (2004) Mandibular third molar removal: Risk indicators for extended operation time, postoperative pain, and complications. Oral Surgery, Oral Medicine, Oral Pathology, Oral Radiology and Endodontology, 97, 438-446. doi:10.1016/j.tripleo.2003.10.018

[25] Rood, J.P., Murgatroyd, J. (1979-80) Metronidazole in the prevention of dry socket. British Journal of Oral Surgery, 17, 62-70. doi:10.1016/0007-117X(79)90009-X

[26] Al Jadid, O.G. (2003) An investigation in the incidence of dry socket and the factors affecting the incidence. 
JRMS, 10, 33-39.

[27] Bortoluzzi, M.C., Manfro, R., De-Oliveira, K.C., Colombo, C. and Petry, I.C. (2007) Prevalence of fibrinolitic alveolitis and infection in dental surgery. Revista de Clínica e Pesquisa Odontológica, 3, 115-122.

[28] Ahmed, A., Mohamed, F. and Hattab, K. (2009) Surgical extraction of impacted mandibular third molars: Postoperative complications and their risk factors. Jamahiriya Medical Journal, 9, 272-275.

[29] Cohen, M.E and Simecek, J.W (1995) Effect of gender-related factors on the incidence of localized alveolar osteitis. Oral Surgery, Oral Medicine, Oral Pathology, Oral Radiology and Endodontology, 79, 416-422. doi:10.1016/S1079-2104(05)80120-9

[30] Krekmanov, L. (1981) Alveolitis after operative removal of third molars in the mandible. International Journal of Oral Surgery, 10, 173-179. doi:10.1016/S0300-9785(81)80051-8

[31] Knoedler, D. and Stanmeyer, W. (1958) Dental observations made while wintering in Antarctica, 1956-1957. Journal of Dental Research, 37, 614-622. doi:10.1177/00220345580370040701

[32] Khorasani, M. (2006) The prevalence and risk factors of dry socket in dental surgery clients following tooth extraction at Qazvin faculty of dentistry. Qazvin University of Medical Sciences, 10, 29-35.

[33] Chuang, S.K., Perrott, D.H., Susarla, S.M. and Dodson, T.B. (2008) Risk factors for inflammatory complications following third molar surgery in adults. Journal of Oral and Maxillofacial Surgery, 66, 2213-2218. doi:10.1016/j.joms.2008.06.067

[34] Yuasa, H., Kawai, T. and Sugiura, M. (2002) Classification of surgical difficulty in extracting impacted third molars. British Journal of Oral and Maxillofacial Surgery, 40, 2631.

[35] Biesbrock, A.R., Hamlin, J.C., Baker, R.A., Gerlach, R.W., Mc-Clanahan, S.F., Hilton, T.J. et al. (1997) Risk factors for alveolar osteitis following the extraction of impacted mandibular molars. Research presented at the 75th General Session of the IADR, 19-23.

[36] Al-Belasy, F.A. (2004) The relationship of "shisha” (water pipe) smoking to postextraction dry socket. Journal of Oral and Maxillofacial Surgery, 62, 10-14. doi:10.1016/j.joms.2002.11.001

[37] Balaji, S.M. (2008) Tobacco smoking and surgical healing of oral tissues: A review. Indian Journal of Dental Research, 19, 344-348. doi:10.4103/0970-9290.44540

[38] Ritzau, M. and Therkildsen, P. (1978) Antifibrinolytic prevention of alveolitis sicca dolorosa. International Journal of Oral Surgery, 7, 534-540. doi:10.1016/S0300-9785(78)80070-2

[39] Ruvo, A.T., Shugars, D.A., White, R.P. and Phillips, C. (2005) The impact of delayed clinical healing after third molar surgery on health-related quality-of-life outcomes. Journal of Oral and Maxillofacial Surgery, 63, 929-935. doi:10.1016/j.joms.2005.03.007 